\title{
Productivity Growth, Plant Turnover and Restructuring in the Canadian Manufacturing Sector
}

\author{
by John R. Baldwin \\ Micro-Economics Analysis Division, Statistics Canada \\ and Canadian Institute for Advanced Research
}

No. 87

11F0019MPE No.87

ISBN: 0-660-15590-7

ISSN: 1200-5223

Phone: (613) 951-8588

Fax: (613) 951-5403

Email: BALDJOH@STATCAN.CA

November 1995

Prepared for the conference entitled "Sources of Productivity Growth in the Eighties" at the National Institute for Economic and Social Research, London and to be published in D. Mayes (ed.), Sources of Productivity Growth. Cambridge: Cambridge University Press.

This paper represents the view of the authors and does not necessarily reflect the opinions of Statistics Canada

\section{INTRODUCTION}




\section{ABSTRACT}

Firm turnover occurs as firms gain and lose market share as part of the competitive struggle. The reallocation of market share from one group to another is associated with productivity gain as the less productive lose share and the more productive gain market share. This paper examines the extent to which productivity has been enhanced by firm turnover over the last twenty years. It focuses on the extent to which this process changed during the 1980s and thereby contributed to the slowdown in productivity growth that was experienced by the manufacturing sector.

Keywords: Productivity Growth, Competition, Firm Turnover 


\section{EXECUTIVE SUMMARY}

1) Firm turnover occurs as firms gain and lose market share as part of the competitive struggle. The reallocation of market share from one group to another is associated with a reallocation of employment.

2) Gains in aggregate productivity occur as the less productive lose employment share and the more productive gain employment share. In the 1970s, these gains accounted for a major portion of the increase in productivity experienced by the manufacturing sector.

3) The productivity growth experienced by the manufacturing sector in the 1970s was considerably higher than in the 1980s. Reasons for the productivity slowdown are not well understood.

4) This paper examines whether the slowdown in productivity growth may be attributed to less competition in the 1980s of the type that contributed so much to productivity growth in the 1970s. A slower growth in productivity may have occurred if less market share was being shifted or if the shifts in market share no longer served to transfer employment share from the less-productive to the more-productive plants.

5) To examine the extent to which the intensity of turnover and competition has recently changed, manufacturing plants are divided into those that gained market share and those that lost market share. Those gaining market share are divided into plants that are new (births) and continuing plants that are growing; those plants losing market share are divided into plants that cease to function (exits) and continuing plants that are declining. Then the amount of market and employment share that are transferred during three periods is calculated. These periods are 1973-79, 1979-85, and 1985-90.

6) Considerable market share is shifted from losers to gainers annually during each of these periods. Upwards of 10 percentage points of market share are transferred on an annual basis. About one-quarter of this is the result of entry or exit.

7) If the total amount of market share being transferred is calculated, not by looking at share change each year, but by comparing plants at the beginning and the end of each period, then the cumulative changes are even larger. Continuing plants that gain market share acquire upwards of 13 percentage points over each period. Plants that entered over the period and are still in existence in the final year acquire upwards of 17 percentage points of the market share of an average 4-digit industry.

8) There is no indication that the intensity of the turnover process declined in the latter part of the 1980s. Indeed it became slightly larger. Most of the increase came on the entry side. The cumulative market share that is gained by continuing plants is $14 \%, 15 \%$, and $17 \%$ over the periods 1973-79, 1979-85, and 1985-90, respectively. The market share gained by entrants increased from $18 \%$ in the period $1973-79$ to over $25 \%$ by the period $1985-90$. The same trend occurs in the employment share that is shifted from plants losing market share to those plants that are gaining market share. 
9) Productivity gains occur as a result of this process because plants that lose market and employment share are less productive than those gaining share. The paper also examines whether the difference in productivities of these two groups changed over the period.

10) When the contribution of market share reallocation within continuing plants is examined for the different periods, few differences are revealed. In the first period, continuing plants that gained market share became $26 \%$ more productive than those losing market share. In the last period, they became $28 \%$ more productive. It is estimated that, without firm turnover, labour productivity in the last year of each period would have been $11.1 \%, 13.2 \%$ and $12.7 \%$ lower. The similarity in these estimates across the three periods suggests that changes in the nature of the reallocation process within continuing plants did not contribute to the productivity slowdown.

11) The effect of entry and exit on productivity growth did, however, undergo a change. In the early period, entrants' market-share gains came primarily from exiters' losses. The effect on average productivity was positive since the productivity of exiters was less than that of entrants. In the latter period, entrants gained more market share than was lost by exiters and, thus, took away some market share from incumbent firms - at least in the calculations that generate average labour productivity. The productivity of entrants is less than incumbents and gradually declined over the three periods. Therefore, the net contribution of entrants turned from being positive in the 1970s to being negative in the late 1980s.

12) The effect of larger amounts of entry that consists primarily of small firms has been to increase the percentage of employment in small firms. This result is found across a wide range of manufacturing industries. The labour productivity of these small firms has been increasingly falling behind that of larger firms. The combined effect of an increasing employment share of smaller firms and declining relative labour productivity in this group would have contributed to the productivity slowdown in the last part of the 1980s. 
The competitive process leads to constant growth and decline. At the margin of an industry, firms are entering and exiting. Within the main body of the population, incumbents are in a constant state of flux. Some are gaining market share. Others are losing market share. The manner in which this process is associated with productivity growth in the Canadian manufacturing sector during the 1970s has been outlined elsewhere (Baldwin and Gorecki, 1991; Baldwin, 1995). ${ }^{1}$

This paper extends the earlier work by examining the relationship between productivity growth and turnover for both the 1970s and the 1980s. By doing so, it investigates whether the earlier pattern extends into the 1980s. This is meant to confirm the importance of turnover.

This paper is also intended to investigate the causes of the productivity slowdown that has occurred in the Canadian manufacturing sector in the late 1980s. It investigates the extent to which the nature and the pace of plant turnover has changed and whether the productivity slowdown was related to restructuring.

Examinations of productivity change are not normally conducted at the micro-economic level. The Solow growth literature traditionally examines how input change and output change are related at an aggregate level. By focusing on issues such as the quality and quantity of inputs that are being used by all firms in an industry, it ignores changes occurring within the industrial structure that may be causing trends or cycles in productivity. These changes can take several forms. First, the intensity of competition may differ over time. The extent to which new more productive firms emerge and wrestle market share away from the less innovative may vary considerably across periods, perhaps because of the existence of long-run innovation waves. Another cause of the recent productivity slowdown may originate in basic shifts in industrial structure-but not of industrial structure as it has normally come to be defined, that is, the type of industries possessed by a country. Rather the relative importance of the underlying production entities may change across a wide-range of industries as one type of firm begins to supplant another. Shifts in technology, which make scale and scope economies more or less important, could underlie such changes.

Since the aggregate approach is not well-suited to exploring the type of structural change occurring within industries, this paper uses micro data at the plant level to do so. Plants are divided into those that are growing as opposed to those that are declining. Elsewhere (Baldwin and Gorecki, 1990; Baldwin and Rafiquzzaman; 1994), growth and decline are defined in terms of change in employment. ${ }^{2}$ However, firms that add jobs may not necessarily be increasing output; firms shedding jobs may not necessarily be those who are losing sales. Growth and decline based on job-change is, therefore, a poor taxonomy to use when studying changes in the intensity of the competitive process. An alternate classification is employed here that more closely approximates a concept of success associated with industrial economics. Success and failure are defined in terms of output changes, corrected for industry growth rates; that is, plants are divided into those gaining and losing market share. Plants gaining market share are producing relatively more of the products demanded by consumers in a given industry; plants losing market share are producing relatively less. 3

The first section of the paper outlines the course of output and productivity growth in the Canadian manufacturing sector. The second section discusses the connection between turnover and productivity growth. The third section investigates how the intensity of turnover differs over the three periods and how it has affected productivity growth. The fourth section then investigates 
underlying changes in structure by examining shifts in the relative importance and productivity of different sized plants.

\section{Growth and Productivity in the Manufacturing Sector}

Changes in real GDP and employment in the Canadian manufacturing sector since 1973 are presented in Figure 1. Real GDP in manufacturing increases in the 1970s, declines during the major 
recession in the early 1980s, and then resumes a strong growth in the 1980s. Employment increases in the 1970 s to a peak in 1981, declines dramatically in the recession of 1982, and then grows during the rest of the decade, regaining its 1979 peak only in 1987.

For the purposes of this study, the period from 1973 to 1990 is broken into three sub-periods: 1973-79, 1979-85, and 1985-90. Figure 2 summarizes the differences in the rates of growth in manufacturing real GDP, employment, manufacturing GDP per capita and the growth in total (multi) factor productivity in each of the three sub-periods. The cumulative rate of growth in real GDP declines over the three peri-

Figure 1: Employment and Output in Manufacturing

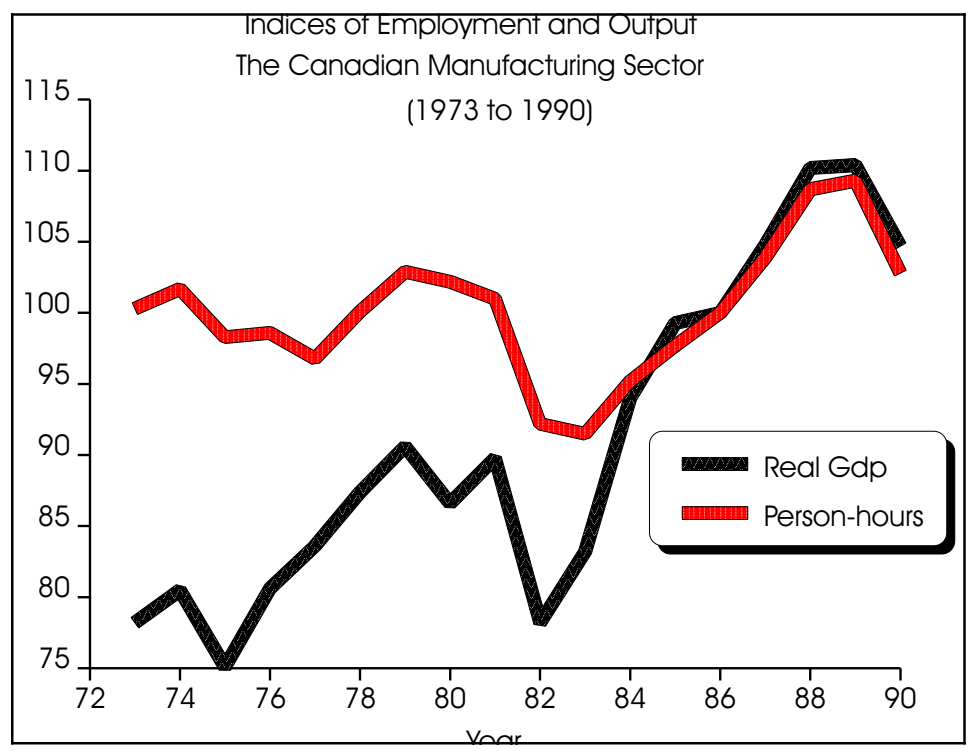
ods-from $15.9 \%$ to $9.6 \%$ to $5.4 \%$. Cumulative employment growth is positive in the first period $(4.8 \%)$, turns negative in the second $(-4.8 \%)$, and then grows by $5.4 \%$ in the last period. Productivity growth is much slower in the third period than in the two earlier periods. GDP per capita grows by $13.1 \%$ and $15.3 \%$ in each of the first two periods, but only by $0.3 \%$ in the last. Total (multi) factor productivity increases by $8.1 \%$ and $12.7 \%$ in the first two periods, and declines by $8.0 \%$ in the third period. ${ }^{4}$

The first period then is characterized by growth in both output, employment and labour productivity.

The second is dominated by a sharp recession with output growing again quickly, but with employment not returning to its pre-recession levels by the end of the period. The last period finds the weakest growth in output and productivity growth.

Previous work (Baldwin and Gorecki, 1991; Baldwin 1995) has demonstrated that plant turnover contributed significantly to productivity growth in the 1970s. Plants gaining share became much more productive than those losing market share. The productivity slowdown in the late 1980s may, therefore, have been related to dramatic changes in

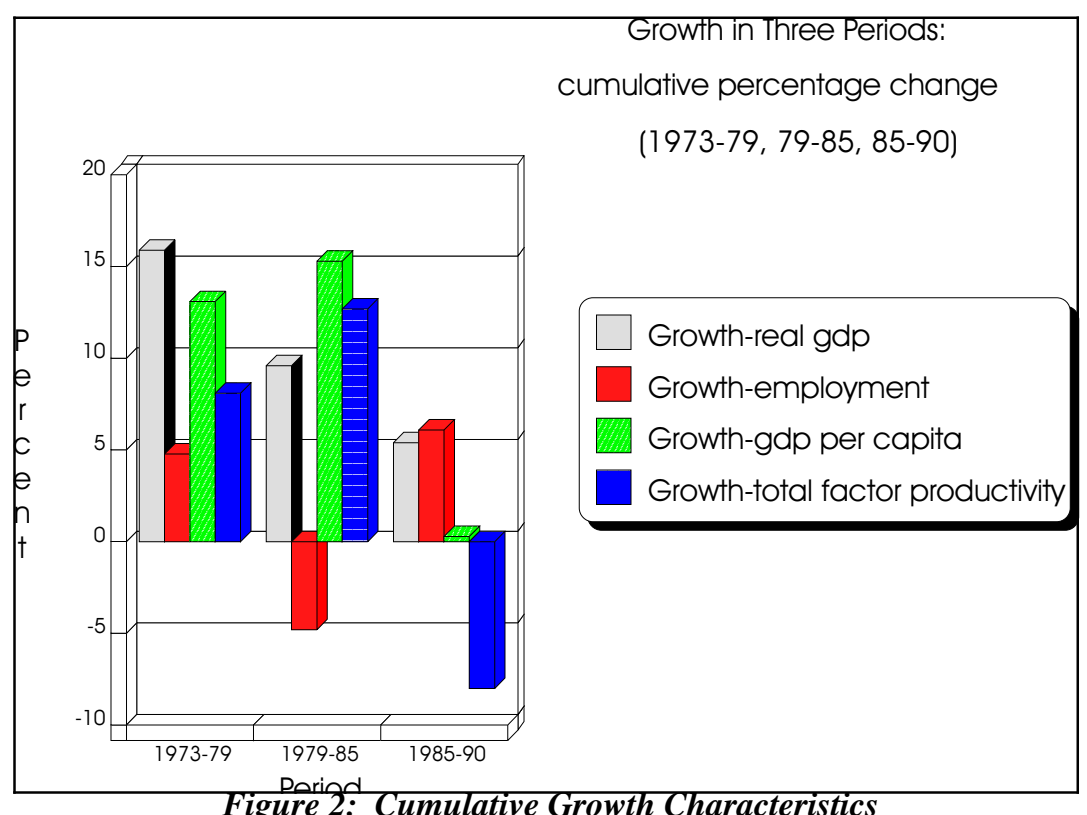


the competitive process in the latter period. The extent to which market share was being transferred to successful new plants could have declined. The productivity gains of these successful plants relative to plants losing market share may not have been as large as was the case previously. Each of these explanations for the productivity slowdown will be examined in turn. But first, the framework for analyzing the effect of turnover on productivity is presented.

\section{The Effect of Turnover on Labour Productivity ${ }^{5}$}

Average labour productivity in an industry is simply the weighted average of the labour productivity of plants in an industry. It equals

$$
\sum_{i=1}^{n} E_{i} \times A P_{i}
$$

where $E_{i}$ is the employment share and $A P_{i}$ is the average productivity of the i'th plant.

Changes in productivity can be traced to turnover to the extent that plants gaining market share also gain employment share and become more productive. The size of the contribution made by producer turnover depends on the extent to which labour share is transferred from the less-productive to the more-productive segment and on the size of the changes in relative productivity of plants gaining and losing market share. This paper examines the nature of this change by concentrating on two sectors. The first includes incumbents that continue throughout the period. The second contains entrants and exits.

Continuers: The population of continuing plants is divided into those that are gaining market share (growers) and those that are losing market share (decliners) over the period of study. The growers, $G$, are those that have found new products or new production processes and are capturing market share from those that are in decline, $D$. The change in market share of the growers, $\Delta M S_{g}$, is just equal to the loss in market share of the decliners, $\Delta M S_{d}$. Growing plants will also experience a change in their employment share $\triangle E S_{g}$, which need not equal the change in market share experienced, especially if their labour productivity $\triangle A P_{g}$ is increasing more rapidly than that of other firms.

Declining plants will experience a change in their employment share $\Delta E S_{d}$ just equal to $\Delta E S_{g}$. Since average productivity is the labour-share weighted average of the productivity of individual groups, changes in average productivity depend both on changes in the relative labourshares of growers and decliners and on changes in their relative productivity.

Denote the employment share of gainers in the final period as $E S_{G 2}$ and in the initial period as $E S_{G 1}$, their labour productivity in the final period as $A P_{G 2}$ and the initial period as $A P_{G 1}$; the employment share of losers in the final period as $E S_{L 2}$ and in the initial period as $E S_{L 1}$, their labour productivity in the final period as $A P_{L 2}$ and the initial period as $A P_{L 1}$. Then the change in productivity between the beginning (period 1) and final (period 2) is:

$\# 1\left[\left(E_{G 2} \times A P G 2\right)+\left(E S_{L 2} \times A P L 2\right)\right]-\left[\left(E_{G 1} \times A P G 1\right)+\left(E_{L 1} \times A P L 1\right)\right]$ 
This can be decomposed in a number of different, but arbitrary ways. One is:

$$
\# 2 \quad\left[\left(E S_{G 2} \times\left(A P_{G 2}-A P G 1\right)\right)+\left(E S_{L 2} \times\left(A P_{L 2}-A P_{L 1}\right)\right)+\left(E S_{G 2}-E S_{G 1}\right)\left(A P P_{G 1}-A P_{L 1}\right)\right]
$$

Another is:

$$
\# 3\left[\left(E S_{G 1} \times\left(A P_{G 2}-A P G 1\right)+\left(E S_{L 1} \times\left(A P_{L 2}-A P L 1\right)\right)+\left(E S_{G 2}-E S_{G 1}\right)\left(A P G 2-A P_{L 2}\right)\right]\right.
$$

The first term of each equation weights productivity in market-share gainers by their employment share. The second term of each equation weights productivity in market-share losers by their employment share. Final-year employment shares are used in equation \#2; initial-year shares are used in equation \#3. The third term is the difference in productivity between gainers and losers weighted by the amount of market share transferred from one to the other over the period.

Decompositions such as these are mechanical. The effect of plant turnover cannot be attributed to a specific source without carefully stating the assumptions that underlie the counterfactual that generates them.

If it is assumed that without the competition which results in market-turnover, employment shares would have remained the same and only the declining sector would have had productivity growth, then it can be demonstrated (Baldwin, 1995) that the amount of productivity growth resulting from this turnover is the sum of the first and third terms of equation \#2. Together these terms capture improvements in productivity because the more productive plants gain employment share (the third term) and because gainers improve their own productivity (term one).

If it is assumed that without the competition associated with turnover, both gainers and losers would have experienced the same productivity growth as actually occurred, but that their shares would have remained the same, then competition and turnover would produce productivity growth as measured by the third term in equation \#2. This term captures just the amount of productivity growth due to shifts in employment share. It provides a conservative estimate of the effect of the competitive process since competition is the stimulus that creates productivity growth in the sector that gains market share and this is not included in the third term.

If it is assumed that without the competition associated with turnover, gainers would have experienced the same productivity improvement as losers and that there would have been no change in the market share of each group, then the gain from turnover can be represented as:

$\# 4\left[\left(E S_{G 1} \times(A P G 2-A P\right.\right.$ New $\left.\left.)\right)+\left(E S_{G 2}-E S_{G 1}\right)(A P G 2-A P L 2)\right]$

where $A P$ New is $A P G 1 / A P L 1 \times A P L 2$. The latter assumes that the ratio of the productivity of gainers to losers in the final period would be just the same as the ratio of gainers to losers in the first period. By doing so, it presumes that productivity growth in the losing sector is essentially exogenous, that it would have occurred irrespective of pressures being exerted on firms in the losing sector by the firms that are wrestling market share from them. Since this is unlikely to be correct, this measure understates the contribution that is made by the turnover process. 
The latter expression is adopted here to measure the effect of plant turnover. It consists of two parts. The first term captures the amount of productivity gain that results from gainers improving their productivity faster than losers. The second captures the portion that is derived from the replacement of losers by gainers-by the substitution of the employment share of losers with the employment share of gainers. In order to provide a benchmark for comparing the effect of turnover on productivity across periods, the value of equation \#4 is divided by final year productivity. This ratio reveals how much productivity in the final year would have been lowered in the absence of turnover.

Entrants: Assumptions regarding the nature of the effect of competition on the replacement process are just as critical for calculating the effect of entry and exit on productivity growth. Entrants are usually less productive than continuing plants. Exits are also less productive than continuing plants. If entrants are assumed to replace continuing plants, entry has a negative effect on average productivity. ${ }^{6}$ If entering plants essentially replace exiting plants, then the contribution of entrants will depend on the relative productivity of entrants and exits. Earlier work (see Baldwin and Gorecki, 1991) suggests that the latter is a more realistic assumption, at least for the Canadian manufacturing sector during the 1970 s.

Denote the market share captured by entrants as $M S_{e g}$, their employment share $E S_{e g}$, and their labour productivity $A P_{e g}$; the loss in market share of exits as $M S_{e d}$; their employment share $E S_{e d}$, and their labour productivity $A P_{e d}$. For the group of continuing plants, denote their labour share in the final period as $E S_{c f}$, and in the beginning period as $E S_{c b}$; their average productivity in the final period as $A P_{c f}$, and in the beginning period as $A P_{c b}$. Then productivity change can be written as:

$$
\text { \#5 }\left[\left(E_{e g} \times A P e g\right)+\left(E S_{c f} \times A P c f\right)\right]-\left[\left(E S_{e d} \times A P e d\right)+\left(E S_{c b} \times A P c b\right)\right]
$$

By assuming that entrants replace exits, we can write the change in productivity ${ }^{7}$ \#6

$$
\left[E_{e g} \times\left[A P_{e g}-A P e d\right]+E S_{c f} \times\left[A P_{c f}-A P c b\right]+[E S c f-E S c b][A P c b-A P e d]\right.
$$

The first term captures the change that is due to the productivity difference between entrants and exits. The third term captures the effect of changes in the relative size of the group of plants that are entering and exiting. The second term represents the growth in productivity due to progress in continuing plants and was discussed above.

In order to provide a natural benchmark against which the productivity of entrants and exits can be measured, the productivity of each will be calculated relative to continuing plants, at the end and the beginning of the periods, respectively. Let

$$
\begin{array}{ll}
\# 7 & A P_{e g}=k_{1} \times A P_{c f} \\
\# 8 & A P_{e d}=k_{2} \times A P_{c b}
\end{array}
$$


Then the larger is $k_{1}-k_{2}$, the greater will be the proportion of total change in productivity that is accounted for by entry and exit.

\section{Data}

In order to investigate the contribution that plant turnover makes to productivity growth, plants that gain market share (gainers) are divided into two groups. The first consists of new plants. The majority of these are greenfield entrants—-firms that enter the industry by building new plants. ${ }^{8}$ The second are incumbents that gain market share. Plants that lose market share (decliners) are divided into exiting plants, the majority of which are associated with firms exiting an industry, and incumbents that lose market share.

Market-share change can be measured either over annual intervals or over longer time periods. In the short run, considerable reversals occur in plant fortunes. Plants that grow rapidly between two adjacent years are likely to reverse direction in the next. Therefore, this study focuses primarily on periods that are long enough to give a sense of the amount of permanent change that takes place, though where appropriate, the annual displacements are also presented for contrast. Three longer-run periods are chosen: 1973-79; 1979-85; and 1985-90. The division of plants into growing and declining segments is done separately for each of the time periods.

The data are derived from a longitudinal file of plants in the Canadian Census of Manufactures that tracks plants over the period from 1973 to 1990 using a consistent set of SIC codes that allow market shares to be calculated over the time period. ${ }^{9}$ Shares are calculated at the 4-digit industry level. $^{10}$

\section{RESULTS}

\section{Market and employment share shifts}

On an annual basis, over 10 percentage points of market share are transferred to gainers from losers. Figure 3 depicts the gain in market share that both continuing plants and new plants capture annually from 1973 to 1990. About three-quarters of the change occurs in the continuing sector. 
- 14 - 
There is very little cyclical change in the amount of share that is transferred annually.

Average annual change per 4-digit industry in the three periods is presented in Table 1. Continuing plant gainers acquire about 8 percentage points of market share but only about 4.5 percentage points of employment share on average. The difference between output and employment share change also applies to the continuing plants that lose market share, where about twice as much output share as employment share is lost. This is consistent with the hypothesis that much of annual change in output share is unanticipated or that labour is a quasi-fixed factor in the short run.

The cumulative output and employment changes for the six-year periods are presented in Table 2. Over the longer periods, considerable market share is transferred from one group to another. Continuing plants that gain market share acquire upwards of 13 percentage points over each period. Plants that have entered over the period and that are still in existence in the final year acquire upwards of 17 percentage points of a 4-digit industry's market share.

Employment shifts do not lag output shifts in the long run by as much as they do in the short run. Plants gaining market share acquire some 10 percentage points of employment share in each period. Losers relinquish more than 11 percentage points on average. Another major difference between the short and the long run lies in the changing relative importance of continuing plants and entrants. In the short run, entrants gain less than one-third of the market share being acquired in total. In the longer-run six-year periods, entrants account for more than one-half of the total. In the short run, entrants gain less than a third of all employment share being transferred; in the longer run, entrants account for two-thirds of the total gain in employment share.

Thus, the competitive process shifts more than 30 percentage points of market share over each of the three periods. Figure 4 depicts the cumulative shifts in market share and the annual averages for each of the three periods. The total being shifted has been increasing over time-from 31.4 percentage points in the first period to 41.7 percentage points in the last period. Most of this

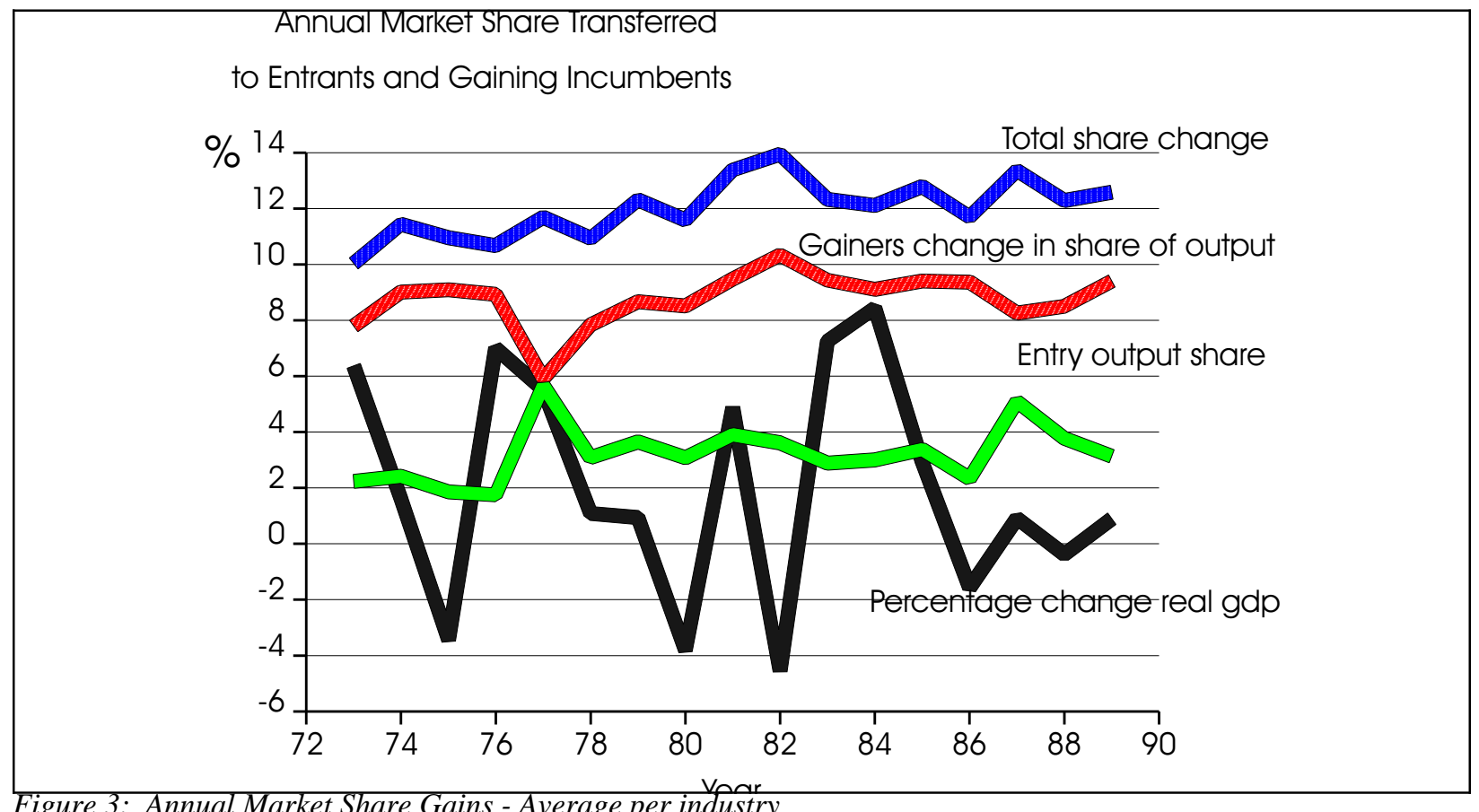

Figure 3: Annual Market Share Gains - Average per industry 
increase is due to higher entry and exit.

Earlier, it was posited that the productivity slowdown in the late 1980s might have been the result of a slowdown in the degree to which the competitive process transferred market share from the less to the more productive. The evidence presented here indicates that the productivity slow-down cannot be attributed to less turnover of market share.

Table 1

Share Change (mean of annual changes in percentage points)

\begin{tabular}{lcccccccc}
\multirow{2}{*}{ Period } & \multicolumn{2}{c}{$\begin{array}{c}\text { Continuing } \\
\text { Gainers }\end{array}$} & \multicolumn{2}{c}{\begin{tabular}{c}
\multicolumn{2}{c}{ Continuing } \\
Losers
\end{tabular}} & \multicolumn{2}{c}{ Entrants } & \multicolumn{2}{c}{ Exits } \\
\cline { 2 - 9 } & $\begin{array}{c}\text { Employ } \\
\text { ment }\end{array}$ & Output & $\begin{array}{c}\text { Employ } \\
\text { ment }\end{array}$ & Output & $\begin{array}{c}\text { Employ } \\
\text { ment }\end{array}$ & Output & $\begin{array}{c}\text { Employ } \\
\text { ment }\end{array}$ & Output \\
\cline { 2 - 9 } $1973-79$ & 4.1 & 8.2 & 4.3 & 8.6 & 3.3 & 3.0 & 3.0 & 2.4 \\
$1979-85$ & 4.5 & 9.3 & 4.2 & 9.2 & 3.6 & 3.4 & 3.8 & 3.0 \\
$1985-90$ & 4.4 & 8.8 & 4.4 & 8.9 & 4.2 & 3.5 & 4.3 & 3.4 \\
\hline \hline
\end{tabular}

Table 2

Share Change (cumulative change in percentage points)

\begin{tabular}{lcccccccc}
\hline & \multicolumn{2}{c}{$\begin{array}{c}\text { Continuing } \\
\text { Gainers }\end{array}$} & \multicolumn{2}{c}{$\begin{array}{c}\text { Continuing } \\
\text { Losers }\end{array}$} & \multicolumn{2}{c}{ Entrants } & \multicolumn{2}{c}{ Exits } \\
\cline { 2 - 9 } & $\begin{array}{c}\text { Employ } \\
\text { ment }\end{array}$ & Output & $\begin{array}{c}\text { Employ } \\
\text { ment }\end{array}$ & Output & $\begin{array}{c}\text { Employ } \\
\text { ment }\end{array}$ & Output & $\begin{array}{c}\text { Employ } \\
\text { ment }\end{array}$ & Output \\
\cline { 2 - 9 } $1973-79$ & 9.6 & 13.6 & 11.5 & 16.1 & 19.5 & 17.8 & 17.6 & 15.4 \\
$1979-85$ & 10.2 & 14.6 & 10.8 & 16.4 & 22.1 & 20.6 & 21.5 & 18.8 \\
$1985-90$ & 10.1 & 16.7 & 14.2 & 19.8 & 28.1 & 25.0 & 24.0 & 21.7 \\
\hline \hline
\end{tabular}

${ }^{1}$ The figures for 1985-90 are augmented by $20 \%$ to make them comparable to the other two periods which were one year longer. 


\section{Productivity}

Entrants vs. exits in the short run. Productivity gains are associated with turnover because plants that are increasing their share of the market become more productive than plants that are losing market share.

Exiting plants tend to be less productive than the population as a whole. They are eliminated by entrants, who are also less productive than the average, but are nevertheless more productive than exits. The part of the turnover process involving entrants and exits increases the productivity of the less productive tail of the plant-size distribu-

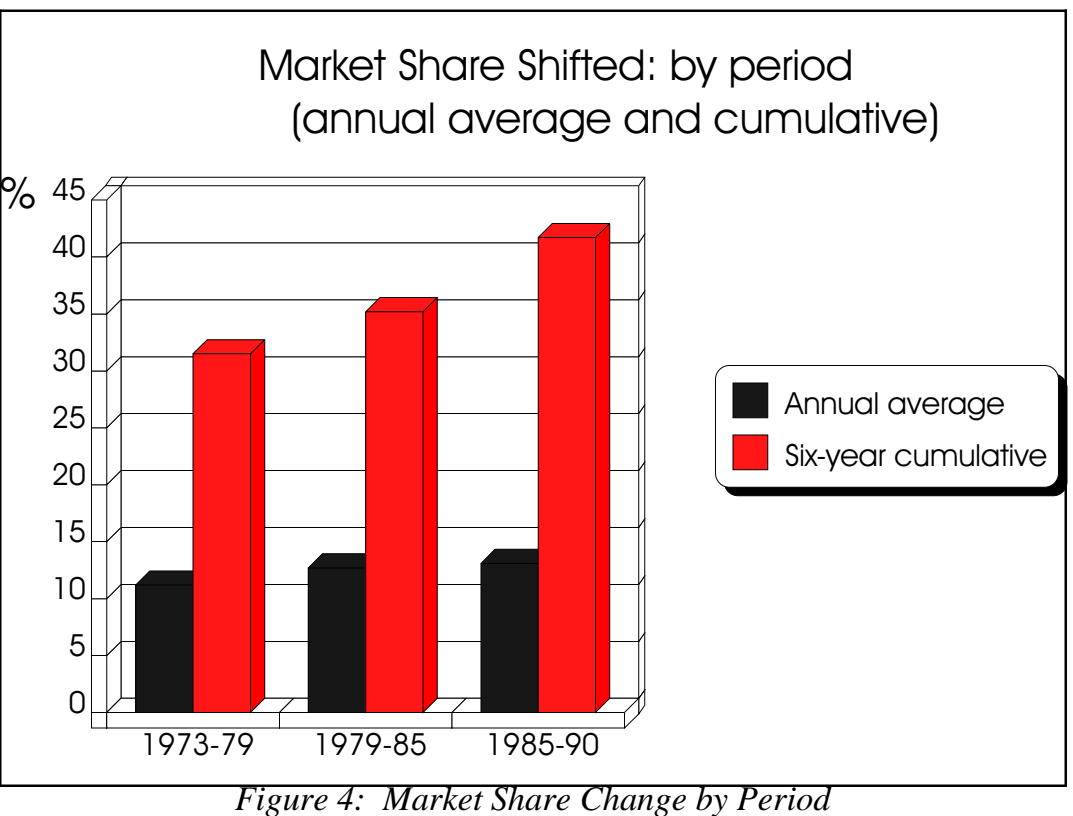
tion.

If the productivity of entrants relative to all continuing plants at the end of the period is about the same as the productivity of exits relative to continuers at the beginning, then the turnover process does not change the relative productivity of this segment. However, the entry and exit portion of the turnover process does increase overall average productivity to the extent that it causes the less productive tail of the plant-size distribution to increase its overall productivity as the main group of the industry advances. When entrants are relatively more productive than exits, turnover from entry contributes even more to the productivity increase experienced by the less productive plants.

In order to investigate the contribution of entry, the average labour productivity (value-added per worker) of entrants and exits and all plants are plotted for the period 1973 to 1990 in Figures 5 and 6. Labour productivity is calculated as the unweighted average across all plants in a category. ${ }^{11}$ Figure 5 plots the productivity for domestically-owned entrants and exits. Figure 6 does the same for foreign-owned entrants and exits. It is useful to distinguish these two groups because their characteristics are so different. ${ }^{12}$

In general, plant entrants and plant deaths are less productive than the population. The difference is less pronounced for foreign than for domestic plants. Indeed, there are several years in which average productivity of foreign entrants exceeds the average for all foreign plants. More importantly, foreign entrants are generally more productive in their first year of existence than are foreign deaths. Thus, foreign-plant turnover, when considered by itself, contributes to productivity growth. 
The productivity of domestic entrants, by contrast, does not as often exceed the productivity of exits. The productivity of domestic entrants does, however, exceed that of exits more frequently in the last half of the period. Nonetheless, the productivity of entrants declines dramatically in the last period, thereby suggesting that the relative productivity of new small firms was declining.

Figure 5: Relative Productivity--Domestic Entrants/Exits

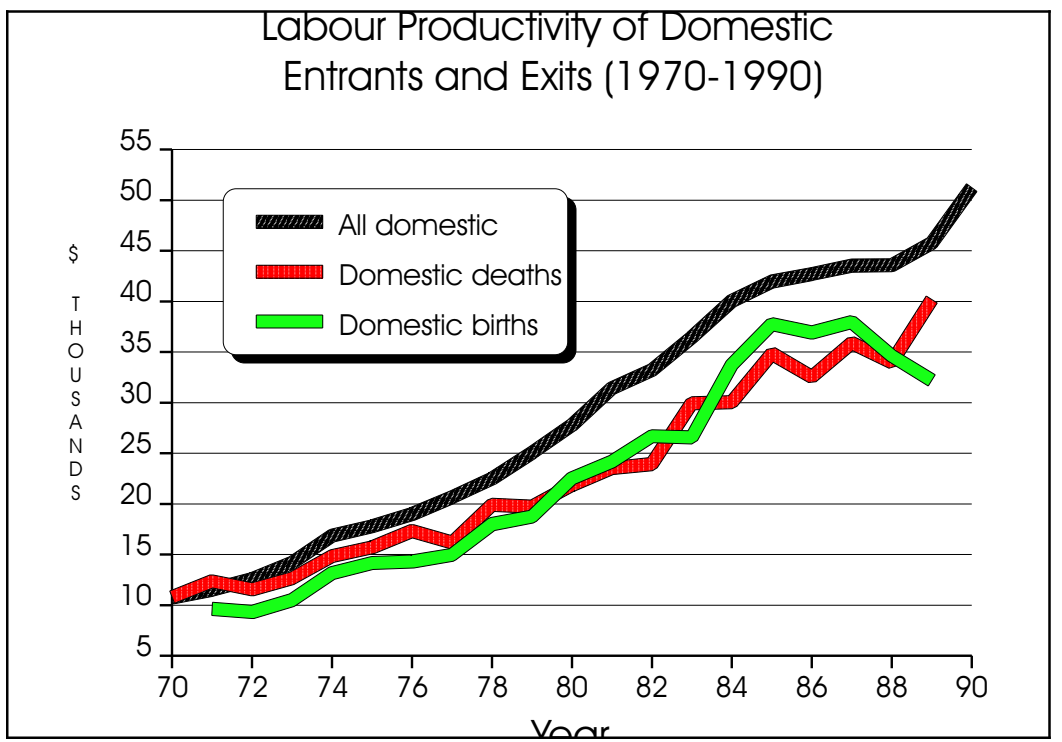

Changes in relative productivity in the longer run. The relative productivity performance of both entrants/exits and continuing plants over the longer 6 -year periods is presented in Table 3. ${ }^{13}$ The first column contains the ratio of the productivity of continuing plants that gain market share relative to continuing plants that lose market share.

In each period, the gainers start at a small productivity disadvantage - the relative productivity ratio is less than one. In each period, the gainers have become considerably more productive than the losers by the end of the period-26\% more productive by $1979,33 \%$ by 1985 , and $28 \%$ by 1990 . The effect of turnover in the continuing sector on productivity is almost the same in each period. Using the formula discussed in the previous section, the productivity gain associated with turnover is calculated to have been $11.1 \%, 13.1 \%$ and $12.7 \%$ of final year productivity. There is no indication then that the intensity of incumbent turnover, or its impact, has changed dramatically over the three periods being considered here.

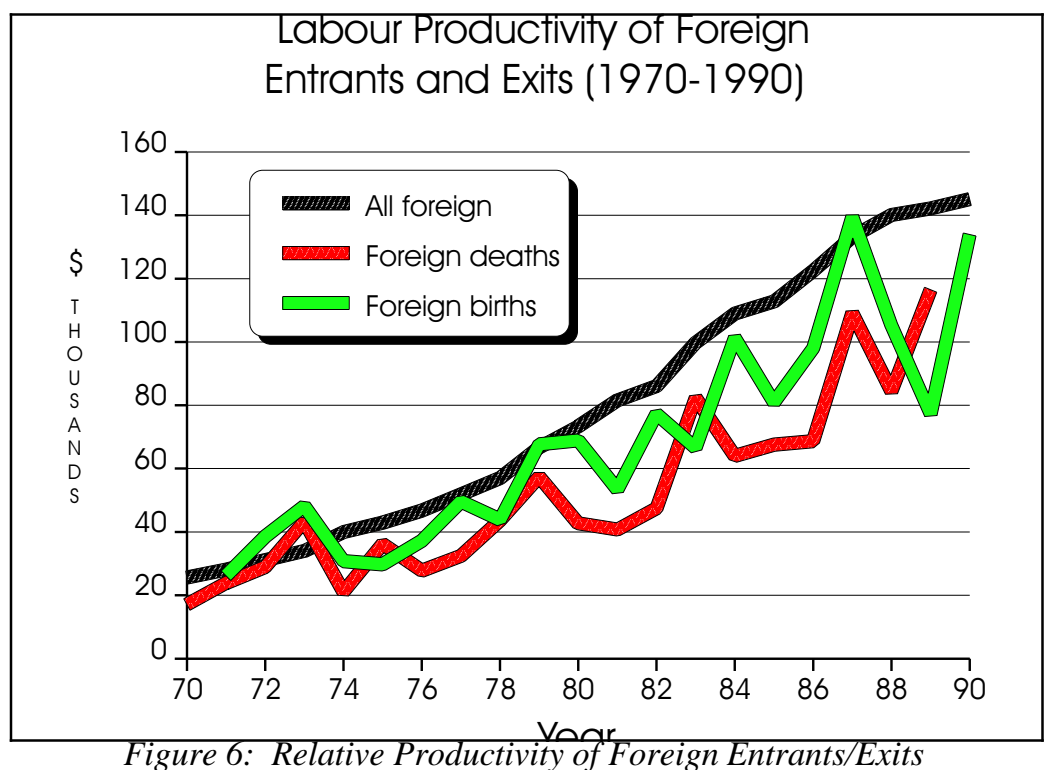

Comparisons of columns 2 and 3 of Table 3 show the longerrun effect of the entry/exit replacement process. In the 197379 period, the productivity of exiting and entering plants was some $81 \%$ of the productivity of continuing plants. During the 1979-85 period, which was marked by a sharp decline followed an equally sharp recovery, the relative productivity of entrants $(84.2 \%)$ exceeds that of exits $(77.5 \%)$. In the final period, the reverse occurs. The relative productivity of entrants is only 
$78.7 \%$ of continuers, while the relative productivity of exits is $81.3 \%$ of continuers. The decline in the relative productivity of entrants indicates that entry began to make less of a contribution to productivity growth by the third period.

Productivity of entrants versus continuing plants. Because the performance of entrants is the one area in which divergences occur across the three time periods, the course of relative productivity of one category of entrants - greenfield entrants ${ }^{14}$ — was investigated in more depth. The productivity of greenfield entrants ${ }^{15}$ relative to continuing firms for each of the first three years after birth was calculated for each of 2354 -digit industries and then averaged. The results are reported for each entry cohort from 1971 to the mid-1980s in Figure 7, along with the average wage rate of greenfield entrants relative to continuing firms. It is evident that the relative productivity of entrants, which was in decline throughout the period, plummeted in the mid 1980s. A major structural shift was occurring in the tail of the firm-size distribution.

Table 3

\begin{tabular}{||c|c|c|c||}
\hline \multicolumn{2}{||c|}{ Relative Productivity Changes over Six-Year Periods } \\
\hline & $\begin{array}{c}\text { Continuing } \\
\text { Gainers/Losers }\end{array}$ & $\begin{array}{c}\text { Entrants/All } \\
\text { Continuers }\end{array}$ & $\begin{array}{c}\text { Exits/All } \\
\text { Continuers }\end{array}$ \\
\hline $1973-79$ & .996 & & 81.3 \\
i) 1973 & 1.263 & 81.2 & \\
ii) 1979 & .977 & & 77.5 \\
\hline $1979-85$ & 1.3304 & 84.2 & 81.3 \\
i) 1979 & & & \\
ii) 1985 & .946 & 78.7 & \\
\hline 1985-90 & 1.277 & & \\
i) 1985 & & & \\
ii) 1990 &
\end{tabular}

\section{Structural Change in the Size Class Distribution}

Three important observations emerge from this investigation. First, turnover is increasing. Second the component that increases the most is entry. Third, there is a long-term downward trend in the productivity of entrants that accelerates in the last period. 
Since entrants are smaller on average than are incumbent plants, an accumulation of new small plants via entry might be expected to have an influence on the relative productivity of small firms in general—unless entrants rapidly improved their lower initial labour productivity and wage rates relative to the population. This in turn would have occasioned a major structural shift in the importance of small as opposed to large plants.

Figure 8 contains the relative share of employment for plants of different sizes-1 to 100,101 -

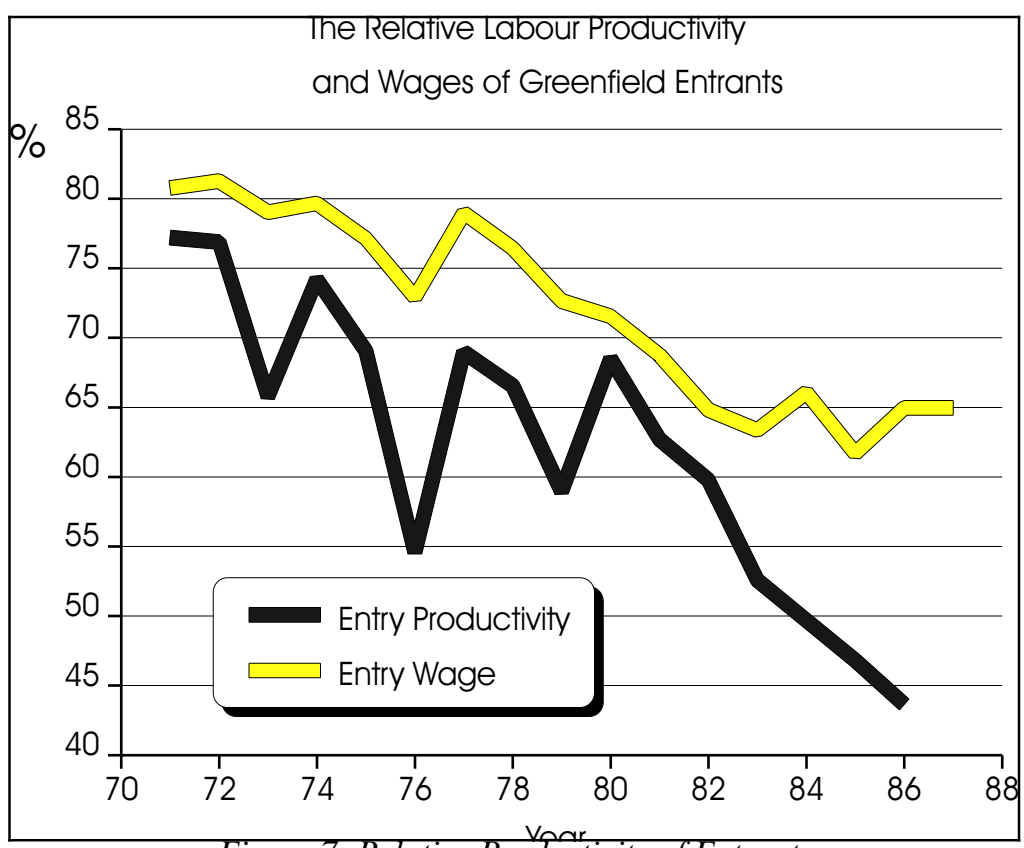

Figure 7: Relative Productivity of Entrants

200, 201-500, and 500+ employees. Plants employing less than 100 employees have increased steadily in terms of employment share over the period-from 35\% in the early 1970 s to over $45 \%$ by the end of the period. The increase was particularly rapid in the last period.

This change is not just the result of a shift of employment to sectors with relatively small plants. To demonstrate this, the manufacturing sector was divided into five major sectors-the natural resource, the labour intensive, the scale-based, the product-differentiated and the sciencebased industries. The five groups are defined on the basis of the primary factors affecting the competitive process. For the resource-based sector, the primary factor affecting competition is access to abundant natural resources.

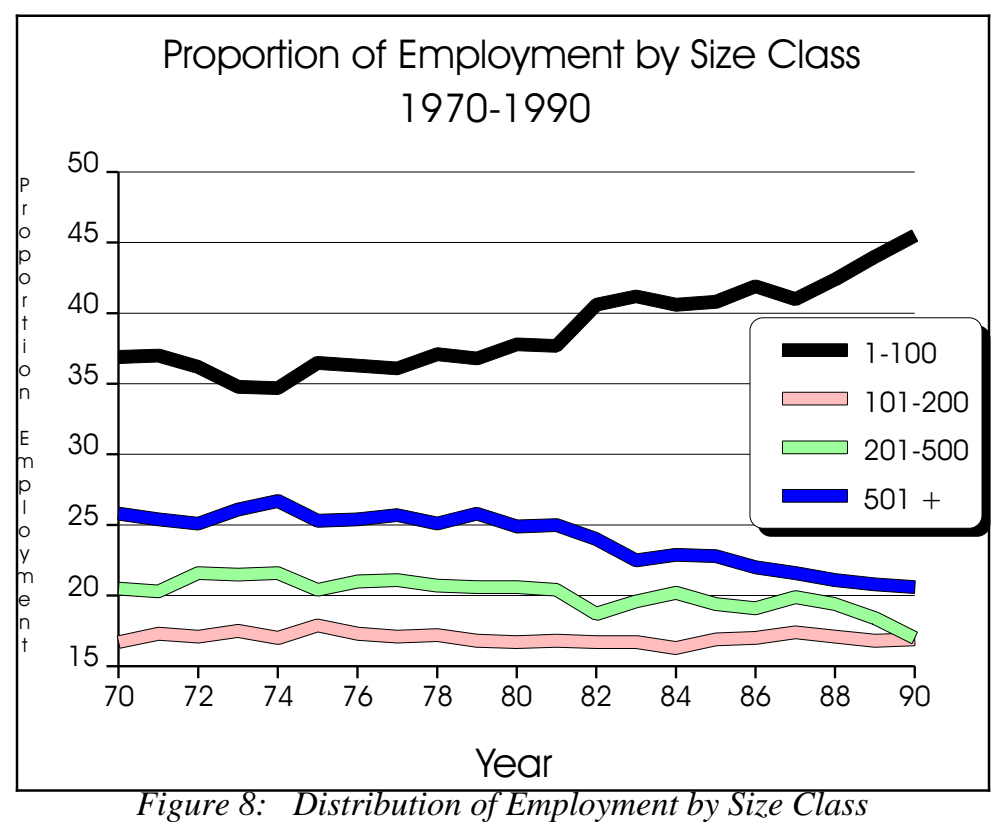
For the labour-intensive sector, it is labour costs. For scale-based industries, it is the length of production runs. For differentiated goods, it is tailoring production to highly varied demand characteristics. For sciencebased industries, it is the rapid application of scientific advance.

The five classifications were initially taken from a taxonomy developed by the OECD (1987) to investigate structural change. The OECD concordance was verified and modified with a discriminant analysis that used some fifty industry characteristics to test the validity of the 
classification scheme as it applied to Canada. ${ }^{16}$ Industries are assigned to this classification based on characteristics such as natural-resource inputs, wage rates, the degree of scale economies, and advertising and research and development expenditures.

The proportion of total employment in plants with less than 100 employees for each of these groups is reported in Figure 9 for the three time periods. The proportion of employment accounted for by small plants is lowest in the scale-based industries where they have less than $30 \%$ of total employment. They are most important in the labour-intensive industries where they have over 50\% of the total by the third period. Nevertheless, in all five sectors, their share increases over the three periods-by some 5 percentage points in the natural-resource sector, 9 percentage points in the labour-intensive sector, 5 percentage points in the scale-based sector, 16 percentage points in the product-differentiated sector, and 3 percentage points in the science-based sector.

By itself, this shift in the relative importance of smaller plants would have slowed down the rate of increase in average productivity. Labour productivity of domestic plants in the smallest size class was about $74 \%$ of average productivity of all plants in the first two periods. But as Figure 10 demonstrates, average productivity of the smallest class fell in the last period to about $68 \%$ of average at the same time as the relative labour share of this size class increased. The relative labour productivity of the other size classes all increased over the same period.

The increase in the relative importance of small plants and their relative productivity decline are important explanations of the productivity slowdown that the Canadian manufacturing sector experienced in the late 1980s. An increase in the relative employment share over the entire period from about $28 \%$ to $35 \%$ combined with a decline in productivity relative to the entire population from $74 \%$ to $68 \%$ of the population would have dragged labour productivity down by 5 percentage points. This has to set against the drop in labour productivity growth rates from an average of $14.2 \%$ in the first

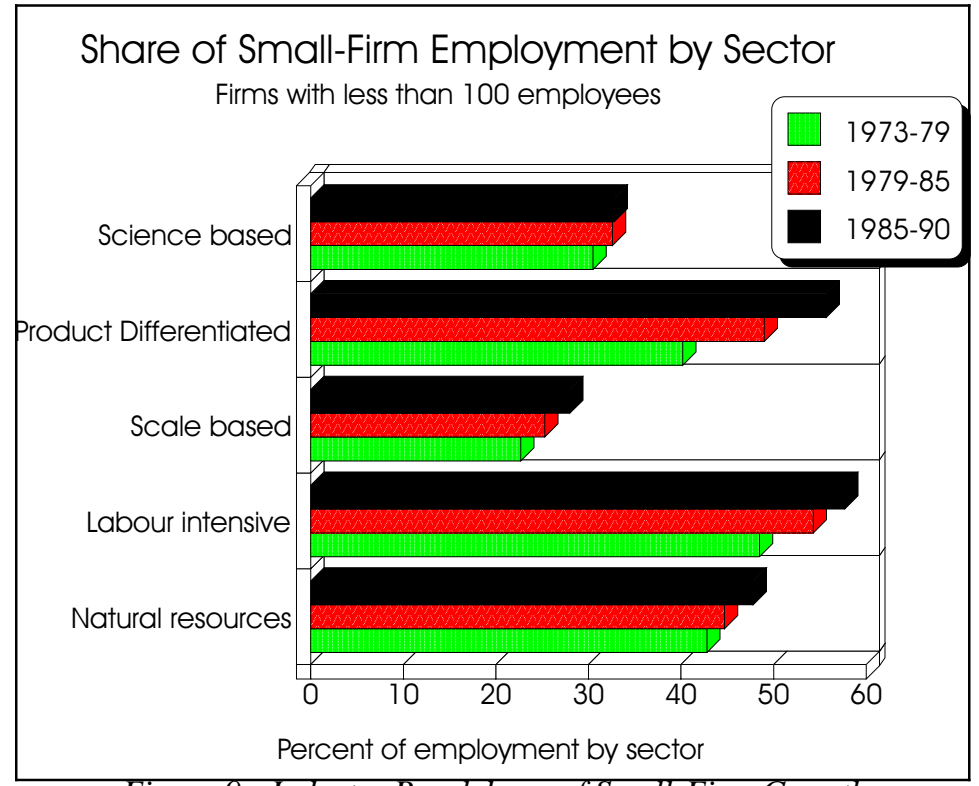
two periods to only $1.1 \%$ in the last period. 


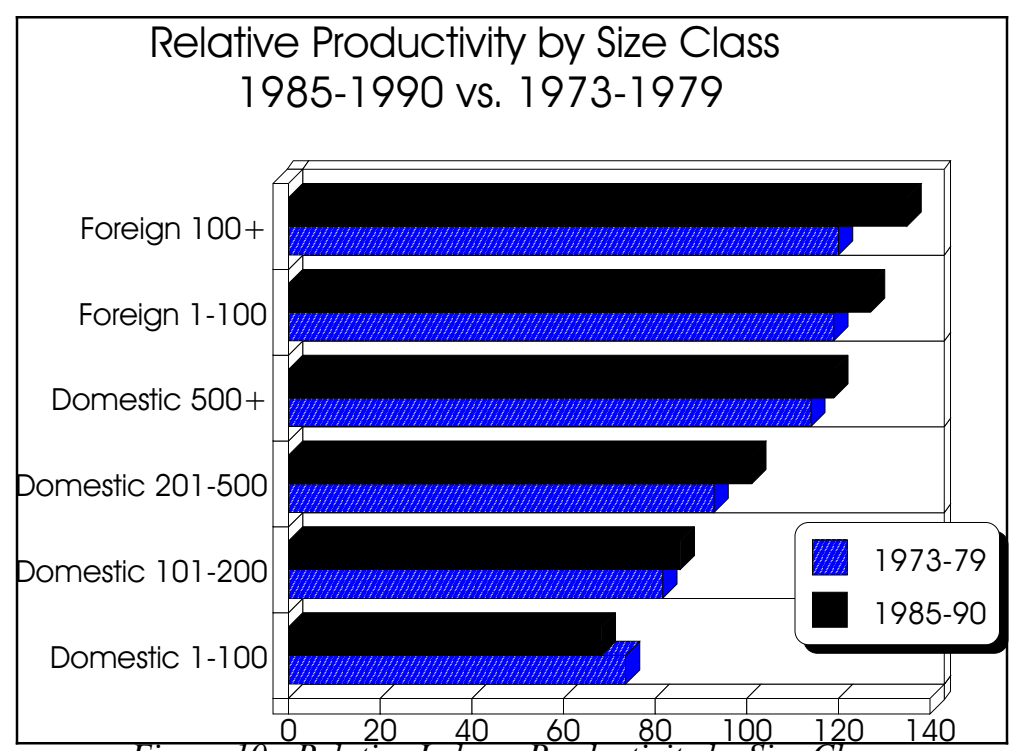

Figure 10: Relative Labour Productivity by Size Class 


\section{CONCLUSION}

This paper asks how firm and plant turnover contribute to changes in productivity and whether there are discernible differences in the amount of turnover in the 1980s compared to the 1970s. The paper finds that the normal growth and decline that occurs in incumbents has not changed appreciably over the three periods, nor has its effect on productivity. In contrast, the entry and exit process is characterized by several marked differences. First, it has become larger. Secondly, the share of entrants now exceeds that of exits. This means that entrants are now supplanting not just exits as they did in the earlier period; they are also gaining share at the expense of incumbents. Third, the relative productivity of entrants, which has been decreasing throughout the period, plummeted markedly in the last period.

There are two interpretations of the causes of turnover-of the shifting importance of different groups of plants. In the first, plants that become more efficient, or that become more productive, supplant those that are less productive. At the margin of an industry, new plants supplant exiting plants. In the main body of an industry, incumbents who find better ways of producing products take market share away from others. The superior production techniques and the better products of the former are all reflected in improved productivity and, therefore, turnover is associated with improvements in productivity.

But this is not the only dynamic force at work that can cause shifts in production activities from one group to another. Changing international comparative advantage may cause the eclipse of one group of producers and the rise of another. Competition for resources, of course, still takes place and facilitates the shifts of employment from one group to another. However, in this scenario, employment may not necessarily shift from low productivity to high productivity or from low wage to high wage plants.

Of course, the two forces may operate simultaneously. If the comparative advantage of a country should improve in high value-added industries, plants that expand will also be the more productive. But the opposite may also occur.

The evidence that has been adduced herein strongly suggests that a restructuring phenomenon has been occurring in the Canadian manufacturing sector, with small less productive plants gaining employment share at the expense of the more productive. This is a phenomenon that has occurred in all three periods studied; but it has increased markedly during the late 1970s.

The reemergence of small-scale production has occurred in a number of western countries (Loveman and Sengenberger, 1991). This phenomenon may be the result of changing technologies which allow small plants to compete with large plants by using less capital-intensive technologies (Carlsson, 1988). The sudden increase in the importance of small Canadian plants in the late 1980s may have also resulted from the undervalued dollar of the early 1980s, which could have induced small, primarily domestic firms to expand unduly. If it is the latter, a major correction in the plant-size distribution should emerge from opposite movements that occurred in the Canadian exchange rate in late 1980s and in the recession of the early 1990s which would have hurt small plants especially hard. In any case, the reason for the rise of the small plant segment bears further investigation. 


\section{NOTES}

1. For other studies that examine the effect of turnover on productivity, see Hazledine (1985), Griliches and Regev (1992), Baily, Hulten and Campbell (1992).

2. See Bailey, Bartelsman, and Haltiwanger (1994) for a example of this approach.

3. As with all unidimensional statistics, market-share change will falsely classify some success stories. But it is probably better than job-change for measuring the intensity of competition. For a multidimensional measure of success, see Baldwin et al. (1994).

4. These are derived from Statistics Canada (1992).

5. Labour productivity provides the focus of this study for three reasons. First, there is a close relationship between changes in market share and relative labour productivity (Baldwin 1995). Second, labour productivity can be measured with greater accuracy than total (multi) factor productivity. Third, the productivity slowdown occurs in both labour and multifactor productivity.

6. This is the assumption that Hazledine (1985) makes.

7. Baldwin and Gorecki (1991).

8. See Baldwin and Gorecki (1990) for a breakdown of new plants between continuing plants and greenfield entrants.

9. See Baldwin (1995) for a description of the data. For the purpose of this study, all plants in manufacturing were used except those which were classified as head offices. Market share is calculated using manufacturing output; employment is the sum of all salaried and production workers.

10. In Canada, there are 235 industries in the longitudinal files that are consistently defined over the period of study.

11. Since the averages were calculated across all plants, the lower average productivity of entrants will be the result partially because entrants are less productive than plants in the same industry and partially because entrants are more heavily concentrated in industries with lower productivity on average. An alternate method is used in Figure 7, where entrants' productivity is calculated relative to continuers' productivity in each industry, and then means are taken across industries.

12. Baldwin and Caves (1992). 
13. These are means of relative productivity statistics calculated at the industry level. The relative productivity statistics at the industry level are calculated as employment-weighted labour productivity averages.

14. Greenfield entrants are new plants that are created by firms that are new to an industry.

15. Average productivity of each group was calculated using employment weights.

16. For a more detailed discussion, see Baldwin and Caves (1992) and Baldwin and Rafiquzzaman (1994) 


\section{BIBLIOGRAPHY}

Baily, M.N., C. Hulten and D. Campbell. 1992. "The Distribution of Productivity in Manufacturing Plants". Brookings Papers: Microeconomics

Baily, M.N., E. Bartelsman, and J. Haltiwanger. 1994. "Downsizing and Productivity Growth: Myth or Reality" Discussion Paper 94-4. Center for Economic Studies. Bureau of the Census. Washington.

Baldwin, J.R. 1995. The Dynamics of Industrial Competition: A North American Perspective. Cambridge: Cambridge University Press.

Baldwin, J.R. and R.E. Caves. 1991. "Foreign Multinational Enterprises and Merger Activity in Canada". In L. Waverman (ed.) Corporate Globalization through Mergers and Acquisitions. Calgary: University of Calgary Press. 89-122.

Baldwin, J.R. and P.K. Gorecki. 1990. Structural Change and the Adjustment Process: Perspectives on Firm Growth and Worker Turnover. Ottawa: Economic Council of Canada.

Baldwin, J.R. and P.K. Gorecki. 1991. "Productivity Growth and the Competitive Process: The Role of Firm and Plant Turnover". In P.A. Geroski and J. Schwalbach. Entry and Market Contestability: An International Comparison. Oxford: Basil Blackwell. 244-56

Baldwin, J.R. and M. Rafiquzzaman. 1994. Structural Change in the Canadian Manufacturing Sector: 1970-1990. Research Paper \#61. Analytical Studies Division. Statistics Canada.

Baldwin, J.R., W. Chandler, C. Le, and T. Papailiadis. 1994. Strategies for Success. Ottawa: Statistics Canada.

Carlsonn, B. 1988. "The Evolution of Manufacturing Technology and Its Impact on Industrial Structure: An International Study". Small Business Economics 1:21-37.

Griliches, Z. and H. Regev. 1992. Productivity and Firm Turnover in Israeli Industry: 1979-1988. Working Paper No. 4059. National Bureau of Economic Research.

Hazledine, T. 1985. "The Anatomy of Productivity Growth Slowdown and Recovery in Canadian Manufacturing”. International Journal of Industrial Organization 3: 307-26.

Loveman, G. and W. Sengernberger. 1991. "The Re-emergence of Small-Scale Production: An International Comparison”. Small Business Economics 3: 1-37.

Organisation for Economic Cooperation and Development. 1987. Structural Adjustment and Economic Performance. Paris: OECD

Statistics Canada. 1990. Canadian Economic Observer. July.

Statistics Canada. 1992. Aggregate Productivity Measures. Cat. No. 15-204. Ottawa. 